胃

DegRUTER DOI: 10.2478/v10129-011-0078-y

Muhammad Nadeem ${ }^{1 *}$, Masum Akond ${ }^{2}$, Atif Riaz ${ }^{1}$, Muhammad Qasim, Adnan Younis ${ }^{1}$, Amjad Farooq ${ }^{1}$

Institute of Horticultural Sciences, University of Agriculture, Faisalabad, Pakistan;

${ }^{2}$ Plant Genomics and Biotechnology Lab, Department of Biological Sciences,

Fayetteville State University, Fayetteville, NC-28301;

* email. nadeem_daisy905@yahoo.com

\title{
POLLEN MORPHOLOGY AND VIABILITY RELATES TO SEED PRODUCTION IN HYBRID ROSES
}

\begin{abstract}
Fertility of hybrid tea roses is often reduced due to their interspesific origin but also to intensive inbreeding. New genotypes used as pollen donors represent an economic risk for a breeding program, as their influence on seed production is unknown. In this study 9 garden rose genotypes were selected from a company database as high fertile or low fertile male parents, according to the number of seeds per hybridization. Pollen morphology and in vitro germination of the selected genotypes were characterized. Pollen was either small (mean diameter $=30 \mu \mathrm{m})$, shrunken, and irregular (abnormal), or large (mean diameter $=30 \mu \mathrm{m})$, elliptical and crossed by furrows (normal). High correlations were found between the number of seeds produced per hybridization and the pollen diameter $(\mathrm{r}=0.94)$ or the percentage of normal pollen $(\mathrm{r}=0.96)$. In order to evaluate the predictive power of the models, we conducted regression analyses and performed a validation experiment on genotypes not present in the database and without background information on fertility. Pollen diameter and percentage of normal pollen were characterized and fitted in the regression models for seed set predictions. Validation with an independent dataset gave a good prediction for $83.3 \%$ of the data. This indicates that using either the mean pollen diameter or the percentage of normal pollen resulted in effective fertility prediction. Moreover cluster analysis of the data classified all the cultivars into various groups with varying fertility. This tool could enhance the genetic variability in crossings between hybrid tea roses, thus creating possibilities for less economically risky exploitation of new tetraploid genotypes as male parents.
\end{abstract}

Key words: crossing, fertility, pollen grains, rosa $\times$ hybrida

Communicated by Andrzej Aniot 


\section{INTRODUCTION}

In most modern breeding programs, the creation of new rose hybrids involves a series of steps that include controlled pollination followed by the fertilization of the ovary, fruit set and hip formation, seed maturation, germination and surviving of new plants. Additionally, the compatibility of the two parents must be considered a factor. To avoid the risk of very low seed production, rose breeders chose male parents with the desired characteristics (Zlesak, 2006) for their known fertility (i.e., number of seeds produced per hybridization). Different rose species and cultivars have varying level of fertility (Zlesak, 2009) variation in fruit and seed set are due to pollen viability rather than incompatibility (Visser et al., 1977a). Breeders favor the most fertile progenitors as pollen and/or seed donors (Zlesak, 2006). Low male fertility in the roses can be overcome by applying repeating and large amount of pollens to female parents but selection of amenable female parent is difficult (Zlesak, 2009). There are many intrinsic and extrinsic factors which also affect the fertility. Age of the flower at the time of the pollination available resource like competition ploidy levels and incompatibility systems are the intrinsic factors while amount and condition of pollen used at the time of pollen transfer to stigma and environmental conditions like temperature, humidity, rainfall, flowering season are the extrinsic factors (Faegriand, Pijl, 1979, Stephenson, 1981, Lee, 1988, Lloyd, Schoen 1992, Proctor et al., 1996).

Several studies concerning pollen germination and pollen tube size in vitro or in vivo (considering the hip set or the mean number of seeds per hip) were carried out with the aim of improving sexual reproduction of roses (Visser et al., 1977a, b, DeVries, Dubois, 1987, Gudin, 2000, Gudin, Arene, 1991, 1992, Gudin et al., 1991a, b, Zlesak et al., 2007). Visser et al. (1977) and Voyiatzi (1995) obtained the best pollen germination percentage with a sucrose concentration of $15 \%$ for hybrid tea roses. Khan (1988) suggested a concentration of $20 \%$ for R. rugosa Thunb. However, Koncalova (1975) reported a higher germination percentage for $R$. hugonis Hemsl., with 30, 35 and 40\% sucrose. Darwin (1884) measured the pollen diameter of 44 species, observing how pollen size was positively correlated to the distance between the surface of the stigma and the transmission tissue of the style. Several studies on pollen characters have been investigated in other species including Olive (Javaday, Arzani 2001), Date palm (Mortazavi et al., 2010), family Triticeae (Arzani et al., 2000) and flowering plants (Stome et al,. 2013).

Breeders do labor-intensive hand hybridization naturally and wish to get high numbers of seeds and as many seedlings as possible. Sexual reproduction in roses, seed set and seed germination are thus of particular interest to breeders (Gudin, 1995). Information of rose pollen fertility can save labor and money to individual breeders who know their own germplasm collection. Most studies on fertility have been performed on cut roses, as they are the most important commercial group. No studies carried out on roses have focused in this study, nevertheless it can be expected that this data on fertility can be useful for other types of roses. The main aim 
of our study was to investigate the relationship between pollen characteristics (morphology, viability and germination) and fertility for seed production. Effect on different sucrose media on pollen germination also studied. This study will help breeders identify valuable pollen donors and enhance breeding efficiency using pollen of some famous hybrid tea roses.

\section{MATERIALS AND METHODS}

\section{Plant material}

We selected nine popular hybrid tea roses cultivars (Autumn Sunset, Iceberg, Angel face, paradise, Casino, Louise Odier, Grand Margina, Handel and Gruss-anTeplitz (Table 1), from the 'rose research project' field of the University of Agriculture, Faisalabad, Pakistan. All selected cultivars were tetraploid except Ice berg which was triploid. After one year of growth they were headed back equally in the month of October. New flushes triggered in the month of December and reached to terminal floral buds in the month of February which led to flowers in the month of April. We then investigated pollen morphology and germination of the selected genotypes and correlated this data with fertility parameters including seeds per hybridisation, mean seed germination and mean seed germination per hip.

Quantitative characters of anthers and pollen

\begin{tabular}{lccc}
\hline \multicolumn{1}{c}{ Cultivar } & $\begin{array}{c}\text { No. of Anther/flower } \\
- \text { mean }\end{array}$ & $\begin{array}{c}\text { No. of pollens/anther } \\
- \text { mean }\end{array}$ & $\begin{array}{c}\text { Pollen size (L/D) * } \\
- \text { mean }\end{array}$ \\
\hline Autumn Sunset & $85.000 \mathrm{a}$ & $1358.3 \mathrm{bcd}$ & $1.1933 \mathrm{a}$ \\
Ice Berg & $102.00 \mathrm{c}$ & $1078.7 \mathrm{e}$ & $1.0833 \mathrm{a}$ \\
Paradise & $88.000 \mathrm{~d}$ & $1537.0 \mathrm{ab}$ & $1.1667 \mathrm{a}$ \\
Angel Face & $130.67 \mathrm{a}$ & $1588.7 \mathrm{ab}$ & $1.1100 \mathrm{a}$ \\
Casino & $90.333 \mathrm{~d}$ & $1187.0 \mathrm{cde}$ & $1.1100 \mathrm{a}$ \\
Louise Odier & $24.333 \mathrm{e}$ & $1131.3 \mathrm{de}$ & $1.1100 \mathrm{a}$ \\
Grand Margina & $95.333 \mathrm{~cd}$ & $1394.0 \mathrm{abc}$ & $1.2200 \mathrm{a}$ \\
Handel & $115.33 \mathrm{~b}$ & $1612.3 \mathrm{a}$ & $1.1100 \mathrm{a}$ \\
Gruss-an-Teplitz & $29.667 \mathrm{e}$ & $1248.7 \mathrm{cde}$ & $1.2200 \mathrm{a}$ \\
\hline
\end{tabular}

LSD at $\mathrm{P}=0.05$; Pollen size is ratio of length to diameter it has no Unit

\section{Pollen collection and storage}

For Pollen collection, purification and storage, anthers from tight floral buds from five plants were removed and homogenized. From each cultivar ten flowers were randomly selected and preceded to anther collection in 
separate petri dishes. This task was performed in the evening before sunset in the month of March. The petri dishes were kept in the laboratory at the room temperature $\left(25^{\circ} \mathrm{C} \pm 2{ }^{\circ} \mathrm{C}\right)$. In the morning at $8^{\prime} \mathrm{o}$ clock the pollen were purified by removing dried anther and were kept at $4{ }^{\circ} \mathrm{C}$.

\section{Estimation of pollen traits}

Pollen quantity was estimated as the number of anthers per flower and the number of pollen per anther. Number of pollens per anther was estimated by haemocytometer (Eti 1990, Ercisli 2007). Furthermore pollen length, diameter and size were recorded by using Contrast phase micrometer at $10 \times$ magnification for each cultivar with three replications. For this dry pollen were dusted on a glass slide having no cover slip. Only un-hydrated pollens were used for measuring pollen length, diameter and size by using micrometer.

Pollen viability was estimated by using acetocarmine according to technique as described by Roberts (1979). For each cultivar five slides were prepared and stained and unstained pollens were counted in the field of the microscope. Pollens that darkly stained were considered viable and the pollens that stained not or lightly stained were referred as unviable. Viability percentage was calculated for each cultivar. Pollen germination was carried out in petri dishes by using 10, 15 and $20 \%$ sucrose in $2 \%$ agar media having three replications for each cultivar at $24 \pm 2{ }^{\circ} \mathrm{C}$. Pollen was spread uniformly on the medium with a small paint brush. After 24 hours incubation period, pollen germination percentage was counted under contrast phase microscope. Pollen was considered germinated when a pollen tube reached a length of at least 1.5 times the pollen diameter (Leus, 2005). The mean pollen germination (\%) was calculated as the germination per total number of observed pollen grains on the petri dish. Pollen tube length was also observed for each genotype.

\section{Hybridization and field evaluation}

Hybridization was done using selected hybrid rose cultivars in the field with all possible cross combinations (720) cross combination during the first 10 days of March, 2009. Percentage (\%) of success cross was calculated for each pollen donor parent by keeping the female parent constant. A scale was developed to estimate the fertility of pollen donor parents with crossing success of $61-100 \%$ as highly fertile, $41-60 \%$ as fertile, $21-40 \%$ as moderately fertile and $1-20 \%$ as low fertile or sterile. In the month of August mature hips of successful crosses were collected and dried at room temperature $\left(24 \pm 2{ }^{\circ} \mathrm{C}\right)$. After 20 days seeds were extracted from the hips manually. Seeds were gathered and counted at the beginning of October, 2009. Afterwards seeds were warm stratified at $\left(24 \pm 2^{\circ}\right.$ C) for 1 month and then stored at $4{ }^{\circ} \mathrm{C}$ in the refrigerator. In the month of December seeds were sown in the lath house (Modified greenhouse having green 
net instead of glass roofing). Seeds were also treated with 30\% H2SO4 for 15 min prior to sowing of seeds in the germination trays.

Pollen size and germination data of the selected cultivars were analyzed by a one-way ANOVA using statistical software Minitab.15. Means were compared by LSD test at $\mathrm{P}=0.05$ for multiple comparison. Pearson correlations (r) were calculated between number of anther per flower, number of pollen per anther, pollen size, and pollen viability and germination percentage. If the correlation were significant regression analysis was performed on the data.

\section{RESULTS}

Pollen morphology, quantity, viability and germination varied considerably in all cultivars. Analysis of variance revealed that number of anther per flower $(* * \mathrm{P}<$ $0.001, \mathrm{~F}=87.9)$ and the number of pollens per anther $(* * \mathrm{P}<0.001, \mathrm{~F}=6.05)$ varied significantly in each cultivar however, maximum number of anther and pollens per anther were exhibited by the cultivar Angel face (130.67) and Handel (1612.3), respectively. On average basis the performance of Angel face and Handel was better with respect to both number of anther per flower and number of pollens per anther as shown in the Table 2. Pollen length and diameter did not showed big variations. Overall, same trend was observed in all cultivars. However, the cultivar Iceberg showed little big pollen diameter $(4.333 \mu \mathrm{m})$ as compared to other cultivars. Pollen size (L : D) was almost same in all cultivars hence no significant differences were observed as shown in the Table 1 . Pollen viability is considered as on one of the most important factor in breeding success. Viability of pollens varied significantly in pollens of all cultivars ( $* * \mathrm{P}<0.001, \mathrm{~F}=15.5$ ). Comparison of means of viability percentage revealed that maximum number of viable pollens in term of viability percentage were possessed by cultivar Handel (70\%) followed by 'Grussan-Teplitz' (64\%). The minimum viability of pollens was exhibited by the Cultivar 'Autumn Sunset' having pollen viability of $35 \%$.

Correlation among pollen vigor parameters

\begin{tabular}{lccccc}
\hline Pollen vigor Parameters & $\begin{array}{c}\text { No. of anther/ } \\
\text { flower }\end{array}$ & $\begin{array}{c}\text { No. of pollens/ } \\
\text { anther }\end{array}$ & $\begin{array}{c}\text { Pollen size } \\
{[\mathrm{L} / \mathrm{D}]}\end{array}$ & $\begin{array}{c}\text { Viability } \\
{[\%]}\end{array}$ & $\begin{array}{c}\text { Pollen germi- } \\
\text { nation } \\
{[\%]}\end{array}$ \\
\hline No. of pollens/anther & 0.582 & & & & \\
Pollen size [L/D] & -0.334 & 0.149 & & & \\
Viability [\%] & 0.302 & 0.216 & -0.287 & & \\
Pollen germination [\%] & -0.193 & 0.411 & $0.738^{*}$ & $0.731^{*}$ & \\
Pollen tube length $[\mu \mathrm{m}]$ & -0.115 & 0.536 & $0.733^{*}$ & -0.164 & $0.77^{*}$ \\
\hline
\end{tabular}

Pollen germination was performed at 3 varying levels of sucrose concentration in the controlled conditions. Pollen germination in vitro is an indirect method to esti- 
mate the vigour of pollen donor parents. Pollen germination percentage varied significantly for all cultivars $\left(\mathrm{F}=68.35,{ }^{*} \mathrm{P}<0.001\right)$ and similarly different concentrations of sucrose have varying effect on pollen germination of all cultivars ( $\mathrm{F}=$ $21.22, * * \mathrm{P}<0.001)$. However the interaction between sucrose and pollen germination was not significant. Sucrose concentration having $15 \%$ sucrose proved very effective for best germination results as compared to $10 \%$ and $20 \%$ sucrose. So at all treatments of sucrose the Cultivar 'Gruss-an-Teplitz' performed well with pollen germination of $46.56 \%$ followed by 'Autumn Sunset' having pollen germination of $38.9 \%$. The minimum pollen germination was performed by the cultivar 'Ice Berg" that is triploid with respect to its ploidy level (Fig. 1 and 2)

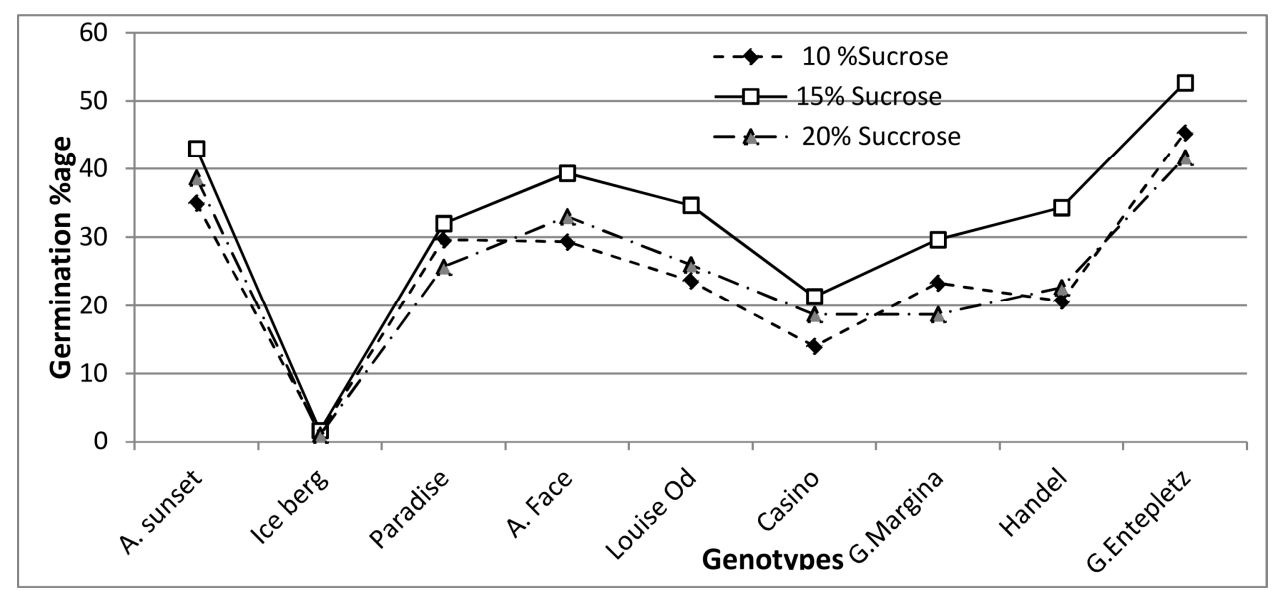

Fig. 1. Pollen germination percentage at various levels of Sucrose

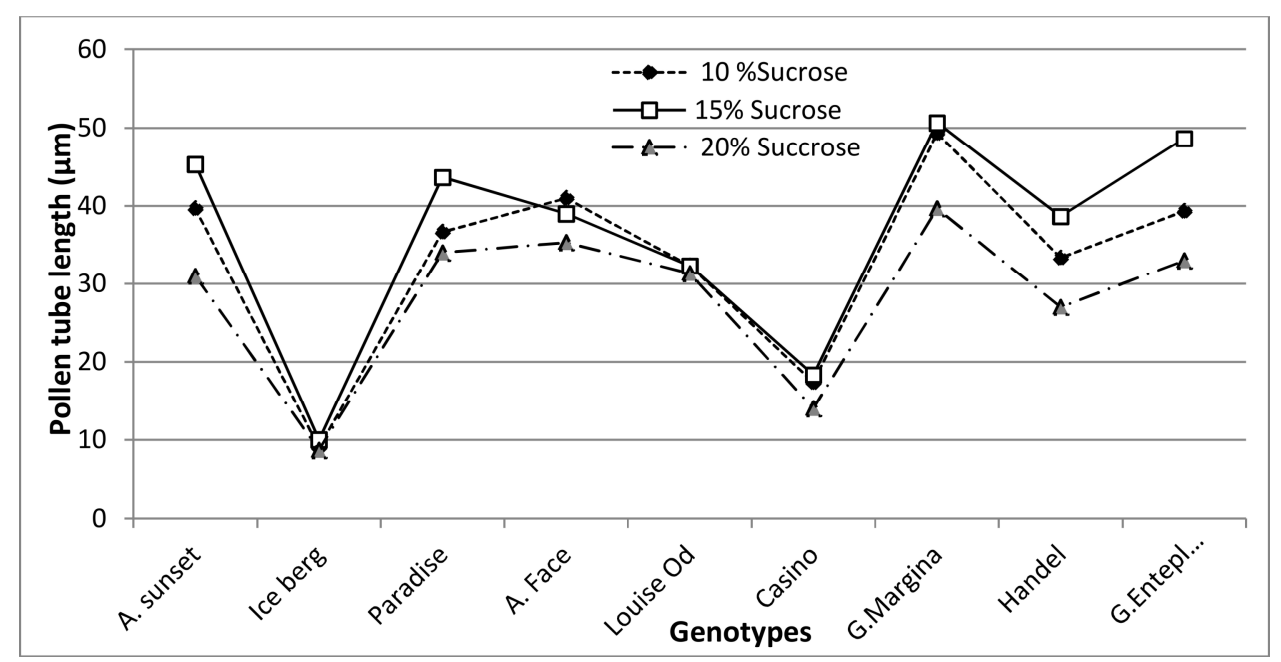

Fig. 2. Pollen tube length at different sucrose concentrations 


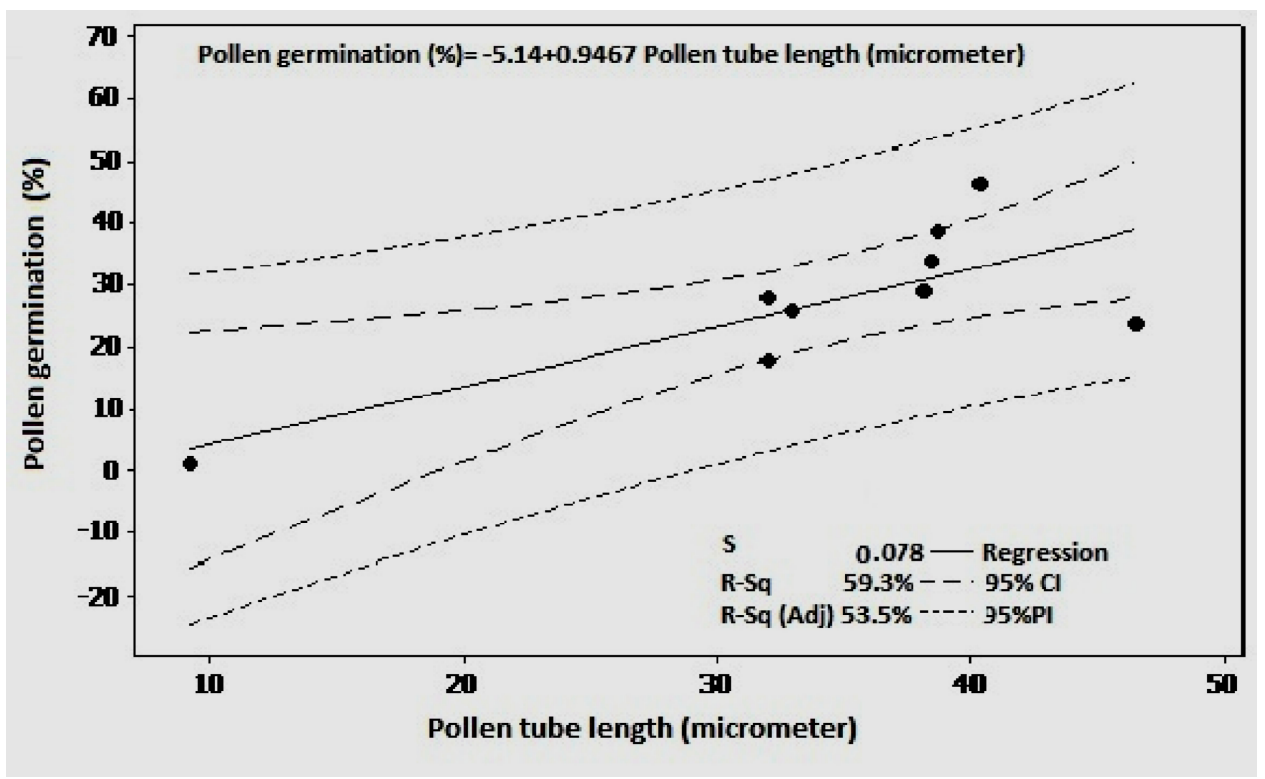

Fig. 3. Regression among pollen germination \%age and Pollen tube length

Pollen tube length is another important parameter to estimate the pollen vigor. Data regarding pollen tube length showed significant variations in ANOVA $(\mathrm{F}=48.48, * * \mathrm{P}<0.001)$. Similar behavior was observed for varying sucrose concentration. The varying conventions of sucrose yielded different response for pollen tube length $(\mathrm{F}=16.59, * \mathrm{P}<0.001)$. On average basis the cultivar 'Grand Margina' yielded maximum pollen tube length of $46.556 \mu \mathrm{m}$ followed by 'Gruss-an-Teplitz' having pollen germination of $40.333 \mu \mathrm{m}$. The minimum pollen tube length of $9.222 \mu \mathrm{m}$ was observed in cultivar 'Ice berg' (Fig.2). The interaction between pollen tube length and sucrose concentration was not significant. However at all levels of sucrose concentration almost every cultivar showed same trend for their pollen tube length but ager media having $15 \%$ sucrose proved very helpful for maximum pollen germination as well as pollen tube length in all cultivars. Pearson correlations between numbers of anther per flower, number of pollen per anther, pollen size $(\mu \mathrm{m})$, and mean pollen viability and germination percentage are presented in the Table 2. Pollen tube length correlated significantly with pollen size and pollen germination percentage. A strong correlation among pollen germination percentage and pollen tube length $(\mathrm{r}=0.77)$ and pollen germination percentage and pollen viability percentage $(r=0.731)$ was exhibited. Pollen germination is also strongly correlated with pollen size $(r=0.738)$. Moreover, the regression analysis between pollen germination percentage and pollen tube length $(\mu \mathrm{m})$ also showed significant results $\left(\mathrm{R}^{2}=8.77\right)$ and regression between pollen tube length and pollen size was not significant $\left(\mathrm{R}^{2}=0.038\right)$ as shown in Fig. 3 and 4 . 


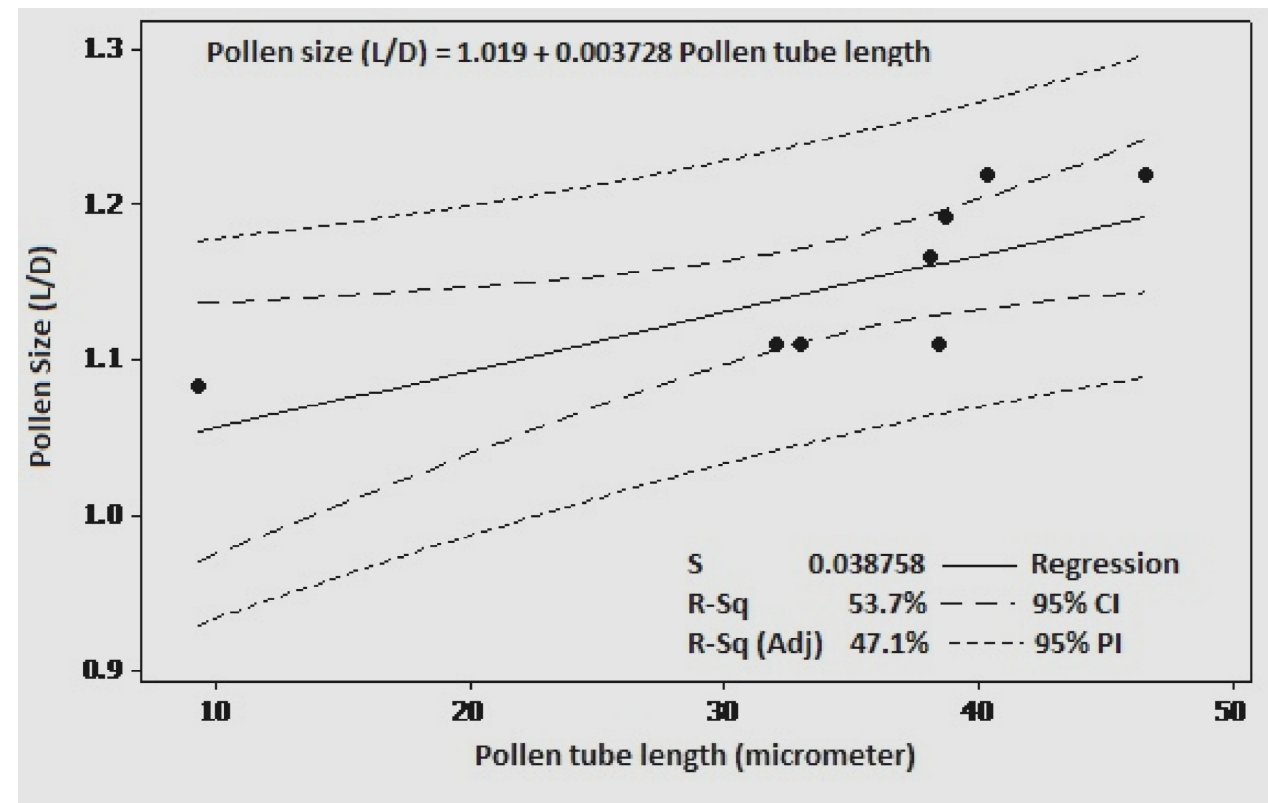

Fig. 4. Regression between pollen tube length and pollen size

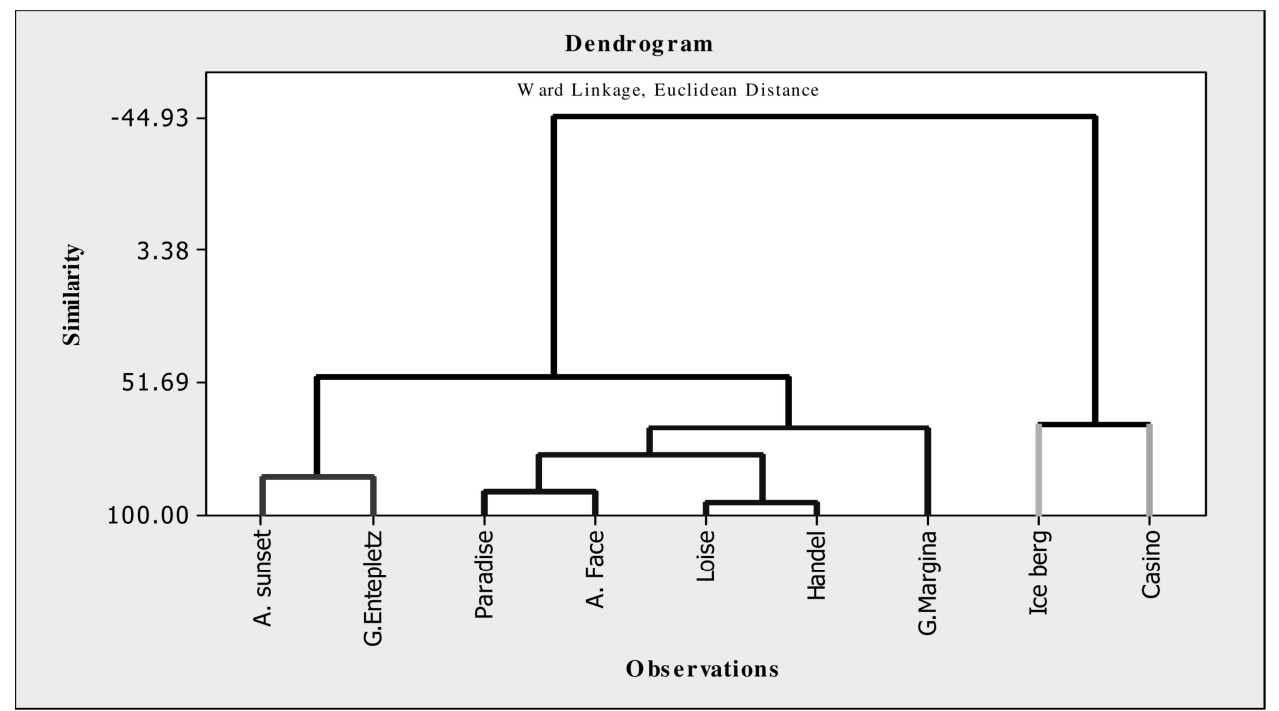

Fig. 5. Tree diagram showing grouping of the cultivars based on pollen physical characters, viability and germination

Cluster analysis of the cultivars based on pollen vigor parameters mentioned above revealed three main groups as predicted in the Fig. 5. Culti- 
vars Autumn Sunset and Gruss an Teplitz condensed themselves in first group while cvs. Paradise, Angel Face, Louise Odier, Handel and Grand Magina behaved in a similar way clustering themselves into second group. Cultivars, Iceberg and Casino were categorized in third group. In group one both cultivars showed $80 \%$ similarity behaved differently from other. Similarly in second group the performance of four cultivars like Paradise, Angel face, Louise Odier and Handel was quite different with respect to the Grand Margina which differed $40 \%$. In third group cultivars, Iceberg and casino also yielded behaved similarly having $60 \%$ similarity. All cultivars also behaved differently for pollen vigor parents as it is obvious from the previous results. In contrast cultivars showing similarity with each other also differed for some of the pollen vigor parameters.

Table 3

Number of crosses made, successful cross and fertility status (It is ensured that the table is based on crosses made only using pollen/ Pollen donor parent)

\begin{tabular}{|c|c|c|c|c|c|c|c|c|c|c|}
\hline 1 & 2 & 3 & 4 & 5 & 6 & 7 & 8 & 9 & 10 & 11 \\
\hline Autumn Sunset & 35 & 38.88 & 80 & 36 & 45 & 31 & 38.7 & 713 & 23 & $\mathbf{F}$ \\
\hline Ice Berg & 58 & 1.33 & 80 & 0 & 0 & 0 & 0 & 0 & 0 & $\mathbf{S}$ \\
\hline Paradise & 51 & 29.11 & 80 & 15 & 18.75 & 13 & 16.25 & 320 & 25 & $\mathbf{L F}$ \\
\hline Angel Face & 60 & 33.88 & 80 & 5 & 6.25 & 5 & 6.25 & 100 & 20 & $\mathbf{L F}$ \\
\hline Casino & 63 & 28.11 & 80 & 12 & 15 & 11 & 13.75 & 253 & 23 & $\mathbf{L F}$ \\
\hline Louise Odier & 42 & 18.00 & 80 & 13 & 16.25 & 9 & 11.25 & 162 & 18 & $\mathbf{L F}$ \\
\hline Grand margina & 51 & 23.88 & 80 & 17 & 21 & 14 & 17.5 & 378 & 27 & MF \\
\hline Handel & 70 & 25.88 & 80 & 43 & 53.75 & 35 & 43.75 & 595 & 17 & $\mathbf{F}$ \\
\hline Gruss-an-Teplitz & 64 & 46.55 & 80 & 22 & 27.5 & 18 & 22.5 & 630 & 35 & MF \\
\hline
\end{tabular}

1 - Pollen donor parent; 2 — Pollen viability [\%] ; 3 - Pollen germination on $15 \%$ Sucrose;

4 - No. of. crosses made; 5 - Successful Crosses; 6 - Success Crossing [\%]; 7 - Total Hip set;

$\mathbf{8}$ - Hip set [\%]; 9 - Total seeds obtained; 10 - Average no of seeds/hip; 11 - Fertility Status

$\mathrm{S}$ - sterile; LF - low fertile, MF — moderate fertile, $\mathrm{F}$ - fertile

All possible combinations of crossing were designed and performed to evaluate the vigor of pollen donor parents. In general each cultivar was given equal opportunity to cross with other eight cultivars. So, maximum percent crossing success (53.75) was exhibited by cultivar 'Handel' which performed best under this crossing regime followed by cultivar 'Autumn sunset' with successful crossing percentage of 45 . The cultivar 'Iceberg, did not performed well, hence all crosses made by this cultivar as a male parent failed (Table 3).

The comparison of various fertility parameters in vitro and in vivo revealed that cultivar "Handel" showing its maximum pollen viability in vitro performed well with respect to giving more crossing success in field as compared to its average pollen germination percentage in vitro conditions. Cultivar "Autumn Sunset" showed also better performance in field as well as in laboratory in spite 
of that fact it has less pollen viability as compared to other cultivars. All the crosses failed when cultivar "Iceberg" was used as pollen donor parent similar to lowest germination percentage in laboratory. The comparison of all pollen donor parents with respect to fertility status in field and laboratory is given in Fig. 6.

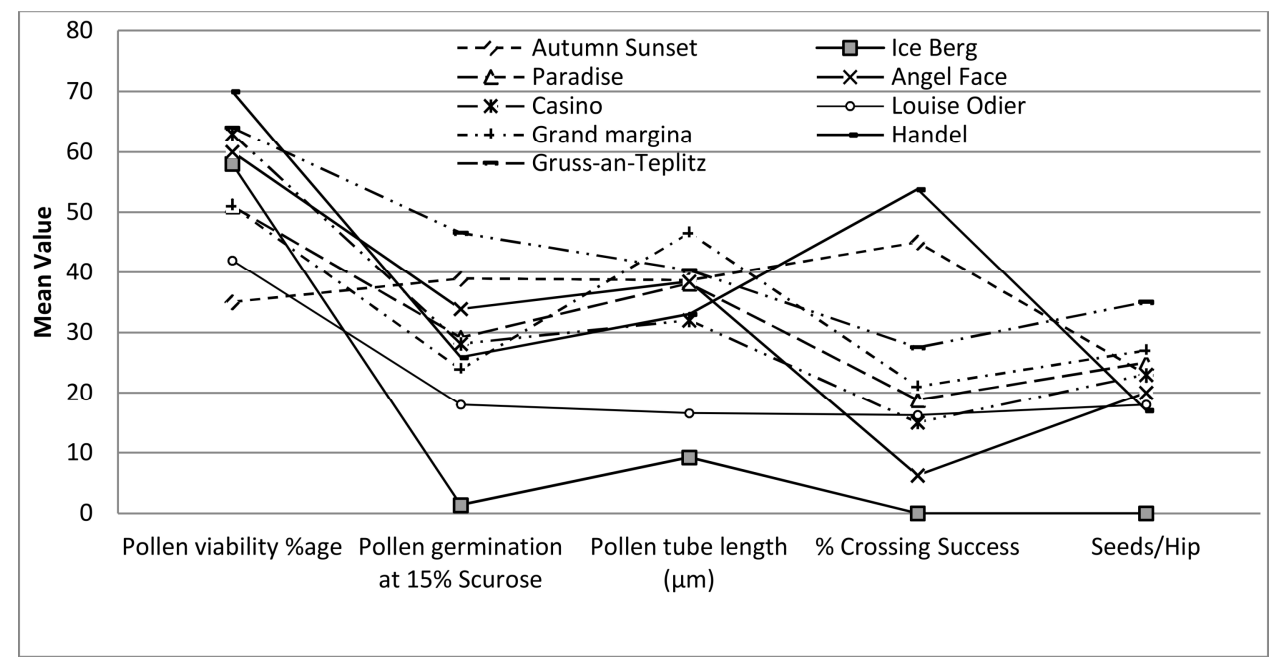

Fig. 6. Relationship between various in vitro and in vivo fertility status of parent cultivars

\section{DISCUSSION}

In order to evaluate the vigor of pollen donor parents in this research program several studies were conducted including, evaluation of cultivars for growth parameters in field conditions, pollen studies in vitro, crossing of cultivars and seed germination. Previously these types of studies are made by (Visser et al., 1977a, DeVries, Dubois 1987, 1996, Ogilvie et al., 1991, Crespel et al., 2006) on different groups of roses. Present research provide a data base of in vitro as well as field analysis of parents used as male, hence it proved to be a good tool to estimate the potential of pollen donor cultivars for breeding program. Pollen studies in vitro are an indirect measure of pollen vigor and fertility in the field. Pollen viability and germination varied considerably in all cultivars as different rose species and cultivars have varying level of fertility (Zlesak, 2009). These variations are correlated to the assumptions of Jacob and Pierret (2000) and Zlesak (2009) who stated that variations in ploidy level of pollen donor parents produce pollens with variable size presenting diversity in fertility status. In contrast to their findings, pollen size did vary considerably in all parent cultivars in spite of the fact that fertility status of pollen varied in each cultivar. These 
variations of fertility in the present roses may be due to many factors including interspecific derivation, meiotic abnormalities and heterozygous polyploid parents hence processes favor the accumulation of deleterious recessive alleles in the progenies (Erlanson, 1931, Ogilvie et al., 1991). One of the examples of dependency of pollen fertility on ploidy level is cultivar "Ice berg" which showed minimum fertility and produced no hips and seeds in all crosses because it is triploid. So it is the different ploidy level rather than variable pollen size which affect fertility of the pollen donor parents. This correlate with the studies conducted by Visser et al., (1977a) on 142 rose species and 88 interspecific hybrids that the mean percentage of normal pollen of di-, tri-, tetra-, penta- and hexaploids was 78, 10, 67, 14 and $42 \%$ respectively. Vasil'eva (2009) while studying the fertility and vitality of pollen observed that the pollen grains of Rosa canina, Rosa corymbifera, Rosa multiflora, Rosa acicularis, Rosa majalis, and Rosa rugosa performed well and got stained with aceto carmine. Highest pollen tube length was calculated in Rosa rgusa followed by Rosa majalis $(184.2 \mu \mathrm{m}$ at $220 \times$ magnification). Pollen germination percentage was 43.18 in Rosa majalis in minimum of $5.17 \%$ in Rosa canina. It was previously reported that pollen viability of $R$. canina, $R$. dumalis, $R$. rubiginosa and $R$. villosa, all belonging to section Caninae, varies considerably among species and pollen viability was recorded between 23 and 45\% (Werlemark, 2000; Ueda, Akimoto 2001). In the present study various concentration of sucrose depicted variable results in pollen germination but $15 \%$ sucrose concentration was very affective in yielding maximum pollen germination percentage in all cultivars on overall basis. Our results are in line those of Richer et al., (2006), Voyiatzi (1995) and Visser et al., (1977a). Moreover, findings are closely to those of Calvino (1951), who obtained better results with a sucrose concentration of $20 \%$ for six species of roses. However, our results are very different from those obtained by Koncalova (1975), who recommended a sucrose concentration of 30 to $45 \%$ for $R$. hugonis.

Other possible variations in performance of pollen donor parent with respect to fertility may arise due to unfavorable environmental conditions as Visser et al., (1977a) observed that the severe environmental conditions during the formation of microgametes can alter the pollen viability potential of rose and, in general, less pollen viability was observed at higher temperatures. In the present studies the hybridization was performed in field condition where temperature in the months of June and July exceeded $45^{\circ} \mathrm{C}$. Gudin, (1992) and Gudin et al., (1991a) also argued that physiological changes occurring in the plants with in the growing period also affect fertility of gametes. Observations made on varieties with the same chromosome numbers e.g. the tetraploids to which the Hybrid Tea-roses belong, also showed distinct differences with respect to fertility. This is similar to the findings of by Calvino (1951) in which out of the 45 tetraploids species and 
42 cultivars have germination of 20 and $30 \%$ respectively had less than $25 \%$ normal pollen.

While having comparison of pollen germination on various sucrose conditions also revealed dependency of cultivars on optimum starch during pollen germination and pollen tube growth as Visser et al., (1977a) revealed that hybrid tea rose pollens germinated well at $15 \%$ sucrose concentration. In the present all cultivars performed well at this level of sucrose. Fertility of the parent rose in terms of pollen germination percentage also depends on the morphological characteristics of pollens as pollen diameter has shown significant correlation $(\mathrm{r}=0.75)$ was observed in the studies made by Pipino et al., (2010). Number of anther per flower and pollen per anther and diameter of pollen is of great concern in getting maximum successful crosses and it varies among species and cultivars. According to Gunes et al. (2005) the number of anther per flower of rose species were between 81.4 ( $R$. villosa) and 148.1 ( $R$. elliptica) and it correlates to the conversion of stamens and pistils into petals and petaloids (Morey, 1959).

\section{CONCLUSION}

It is concluded that it is important to consider the ploidy level in selection of pollen donor parents rather than focusing on pollen size and also more success is achieved if we test the fertility status of pollen donor parents invitro prior to making cross in the field or in greenhouse. Superior quality pollen will lead to a more crossing success, more seed setting and elite progenies.

\section{ACKNOWLEDGEMENT}

We wish to extent our thanks to Higher Education Commission, Pakistan for financial support and Institute of Horticultural Sciences, University of Agriculture, Pakistan, for providing platform and lab facilities to conduct the present research.

\section{REFERENCES}

Arzani, A., Poursiahbidi, M., and Mortazavi S. E. 2000. An acetocarmine staining procedure for chromosome banding studies of immature pollen in Triticeae. J. Agr. Sci. Tech., 2: 167-175

Calvino, E.M. 1951. Ricerche sul pollini del genera Rosa. Ann . Sperimentazio Agraria, 5: 377-407.

Crespel, L., Ricci, S., and Gudin, S. 2006. The production of 2n pollen in rose. Euphytica, 151: 155-164.

DeVries, D.P., and Dubois, L.A.M. 1987. The effect of temperature on fruit set, seed set and seed germination in Sonia x Hadley hybrid Tea-rose crosses. Euphytica, 36:117-120.

Darwin, C. 1884. The different forms of flowers on plants of the same species, 2nd Edn., Murray, J, London.

DeVries, D.P., Dubois and L.A.M. 1996. Rose breeding: past, present, prospects. Acta Hort., 420: 241-248.

Ercisli, S. 2007. Determination of pollen viability and in vitro pollen germination of Rosa dumalis and Rosa vilosa. Bangladesh J. Bot., 36(2): 185-187. 
Erlanson, E.W. 1931. Sterility in wild roses and in some species hybrids. Genetics, 16: 75-96.

Eti, S. 1990. A practical method for the determination of pollen production. J. Agricul. Faculty Cukurova University, 5: 49-58.

Faegririand K., and Van der Pij1, L. 1979. The Principles of Pollination Ecology, Pergamon Press, Oxford.

Gudin, S., and Arene, L. 1991. Influence of the $\mathrm{pH}$ of the stigmatic exudate on male-female interaction in Rosa hybrida L. Sexual Plant Reproduction, 4: 110-112.

Gudin S., and Arene, L. 1992. Putrescine increases effective pollination period in roses. Hort Technology, 2: 211-213.

Gudin, S. 1995. Rose improvement: a breeder's experience. Acta Hort., 420: 125-128.

Gudin, S. 2000. Rose: Genetics and breeding. In: J. Janick (ed.), Plant Breeding Reviews. John Wiley \& Sons, Inc., pp.159-189.

Gudin, S., Arene L., and Chavagnat, A. 1992. Relation entre imbibition, densite, taux de remplissage et faculte' germinative chez l'ake 'ne de Rosa hybrida L. Agronomie, 12: 123-126.

Gudin, S., Arene, L., and Bulard, C. 1991a. Influence of season on pollen quality. Sexual Plant Reproduction 4:113-117.

Gudin, S., Arene, L., Pellegrino, C. 1991b. Influence of temperature and hygrometry on rose pollen germination. Adv Hortic Sci., 5: 96-98.

Gudin, S. 1992. Influence of bud chilling on subsequent reproductive fertility in roses. Sci Hortic, 51:139-144.

Gunes, M., Cekic C., and Edizer, Y. 2005. Determination of pollen quantity, pollen viability and pollen germination in some dogrose species (Rosa section Caninae). Acta Hort., 690: 211-217.

Jacob ,Y., Pierret, V. 2000. Pollen size and ploidy level in the genus Rosa. Acta Hort., 508: 289-292.

Javaday, T., and Arzani, K. 2001. Pollen morphology of five Iranian Olive (Olea europaea L.) cultivars. J. Agric. Sci. Technol., 3: 37-42

Khan, M.A .1988. Studies on the compatibility of six hybrid tea roses. Pak. J. Agric. Sci., 23: 73-78.

Koncalova, M.N. 1975. Studies in Rosa pollen-I: Invitro germination of pollen grains of Rosa hugonsis. Preslia 47:22-25.

Lee, T.D. 1988. Patterns of fruit and seed production. In: J.L. Doust, L.L. Doust (ed.), Plant Reproductive Ecology- Patterns and Strategies Oxford: Oxford University Press 179-202.

Leus, L. 2005. Resistance breeding for powdery mildew (Podosphaera pannosa) and black spot (Diplocarpon rosae) in roses. PhD Thesis, Faculty of Bioscience Engineering, Ghent University, Belgium.

Lloyd, D.G., and Schoen, D.J. 1992. Self and Cross fertilization in Plants. I. Functional dimensions. Int J Plant Sci., 153: 358-369.

Morey D 1959. Observations on the genetics of doubleness in roses. American Rose Annul 44: 113-116.

Mortazavi, S.M.H. Arzani, K., and Moieni, A. 2010. Optimizing storage and in vitro germination of Date Palm (Phoenix dactylifera) pollen. J. Agr. Sci. Tech., 12: 181-189

Ogilvie, I., Cloutier, D., Arnold, N., and Jui, P.Y. 1991. The effect of gibberellic acid on fruit and seed set in crosses of garden and winter hardy Rosa accessions. Euphytica, 52: 119-123.

Pipino, L., Marie-Christine, V.L., Andrea, M., Valentina, S., Annalisa, G., and Leen, L. 2010. Pollen morphology as fertility predictor in hybrid tea roses. Euphytica. DOI 10.1007/s10681-010-0298-5.

Proctor, M., Yeo, P., and Lack, A. 1996. The natural History of Pollination. Portland, Oregon: Timber Press.

Richer, C., Poulin, M., and Rioux, J.A. 2007. Factor influencing pollen germination in Explorer roses. Can J Plant Sci., 87: 115-119.

Roberts, A.V. 1979. Science and roses. The Rose Annual. England: The Royal National Rose Society, 140$146 \mathrm{p}$.

Stephenson, A.G. 1981. Flower and fruit abortion: proximate causes and ultimate functions. Annu. Rev. Ecol., 12: 253-279.

Ueda, Y., and Akimoto, S. 2001. Cross and self compatibility in various species of the genus Rosa. J Hortic Sci Biotech., 76: 392-395.

Vasil'eva, Y.O. 2009. Reproduction systems of representatives of the Genus Rosa L. under conditions of continental Climate. Cont. Prob. Ecol., 4: 361-368.

Visser, T., DeVries, D.P., and Scheurink, J.A.M., and Welles, G.W.H. 1977a. Hybrid tea-rose pollen I. Germination and storage. Euphytica 26: 721-728.

Visser T, DeVries, D.P., Welles, G.W.H., and Scheurink, J.A.M. 1977b. Hybrid tea-rose pollen II. Inheritance of pollen viability. Euphytica 26: 729-732.

Voyiatzi, C.I. 1995. An assessment of the in vitro germination capacity of pollen of five tea hybrid rose cultivars. Euphytica 83: 199-204.

Werlemark, G. 2000. Evidence of Apomixis in hemisexual dog roses, Rosa section caninae. Sexual Plant Reproduction 12: 353-359.

Zlesak, D.C. 2006. Rosa x hybrida. In: N.O. Anderson (ed.), Flower Breeding and Genetics, The Netherlands, Springer, pp. 695-738. 
Zlesak, D.C., Zuzek, K., and Hokanson, S.C. 2007. Rose pollen viability over time at varying storage temperatures. Acta Hort., 751:337-343.

Zlesak, D.C. 2009. Pollen diameter and guard cell length as predictors of ploidy in diverse rose cultivars, species and breeding lines. In: J.A. Taxeira da Silva (ed.), Floriculture and ornamental biotechnology London: Global Science Books, pp. 53-70. 